\title{
A NOVEL APPROACH FOR DESIGN OF PROGRESSIVE DIE FOR SHEET METAL COMPONENTS
}

\author{
SURAJ K. VYAPARI ${ }^{1}$,SHUBHAM R. ZUNGARE ${ }^{2}$, DEVENDRA S. SURYAWANSHI ${ }^{3}$, SYED \\ SAFIUDDIN SYED AZHARUDDIN ${ }^{4}$, PRAVIN R. LOKHANDE ${ }^{5^{*}}$ \\ ${ }^{1,2,3,4}$ UG Student, Mechanical Dept., Sinhgad College of Engineering, Pune, India \\ ${ }^{5}$ Assistant Professor, Mechanical Dept., Sinhgad College of Engineering, Pune, India
}

\begin{abstract}
Design of progressive tools for the sheet metal component is one of the important phase in sheet metal manufacturing. Sheet metal press working process by progressive tools is a highly complex process that is vulnerable to various uncertainties such as variation in progressive tools geometry, strip layout, die shear, material properties, component and press working equipment position error and process parameters related to its manufacturer. These uncertainties in combinations can induce heavy manufacturing losses through premature die failure, final part geometric distortion and production risk. In this work the use of a software namely AUTOCAD and UG-NX for designing a progressive die to manufacture floating contact for the push button system has been incorporated. A progressive die is a multiple station die. In this work we have designed a progressive die which has four stages of operation. The operations are piercing, dimple forming, bending and then blanking. All these operations are performed simultaneously in a single stroke of press, thus enabling the user to obtain the final product in a single stroke.
\end{abstract}

KEYWORDS: Sheet Metal Manufacturing, Sheet Metal Press Working Process, Progressive Tools

Received: Sep 08, 2020; Accepted: Sep 28, 2020; Published: Nov 12, 2020; Paper Id.: IJMPERDOCT202052

\section{INTRODUCTION}

The aim of this research paper was to design progressive die for sheet metal component with less production time, more accuracy and high production rate. The progressive die performs aseries of fundamental sheet metal working at two or more stages during the press running to produce a production part as the strip stock moving through the die surface. The work piece on progressive die travels from one station to another, which enables each operation to be performed at each station. Usually the work piece is retained in the stroke until it reaches the final station, which cuts off the finished piece.

All station work simultaneously at different points along the work strip, which advances on station at each stroke of ram. Thus a complete part is produced with each stroke. Progressive dies generally include blanking and piercing operations but a complicated progressive die can do the operation of bending, forming, curling and heading too.

Each workstation performs one or more distinct die operations, but the strip must move from the first through each succeeding station to produce a complete part. The selection of any multi-operation tool, such as progressive die, is justified by the principle that the number of operations achieved with one handling of the stock and produced part is more economical than production by a series of single operation dies and a number of handling for each single die. 


\section{LITERATURE REVIEW}

The increasing demand for press tools, and progressive dies perform a series of fundamental cutting and forming operations typically on continuous sheet metal strip, or coil, stock. Design of progressive die is a complex and highly specialized procedure, so designer progressive die must have a high level of knowledge on the part that can only be achieved through years of practical experience. Also selection of materials for die components, and modelling of die components and die assembly are major activities for designing a progressive die [1-2]. In progressive die operations are performed simultaneously in a single stroke of press, thus enabling the user to obtain the final product in a single stroke. Then there is principal of metal cutting in which the operations like plastic deformation of sheet metal, then penetration and fracture of sheet metal for the required part. With that the manufacturing the die there components are required like top and bottom plate, trust plate, dowel, fastener, pilots etc [3-4].

The small error at any work station can induce heavy manufacturing losses through die failure, part geometry distortion and production risk. This research deals with designing a progressive die, simulating the blanking and piercing process. By using this die we can produce accurate component [5-6]. An automated design system developed for design of progressive die. The proposed system is organized in 27 knowledge-base modules. The production rule based knowledgebase system (KBS) approach is utilized for constructing the system modules. Modules are user interactive and designed to be loaded into the prompt area of Auto CAD. The system is capable of automating all major activities of design of progressive die such as checking the design features of sheet metal parts, design of strip-layout, selection of progressive die components, modeling of die components and die assembly, and selection of materials for progressive die components [7-9]

\section{MATERIALS AND METHODS}

Design of component is done by study the component and then do reverse engineering on component. After doing reverse engineering the raw strip material is consider, then the preparation of strip layout. Then trail and error for strip layout should be check. Tool and die design is to be prepare. At last the bill of material is to be created.

\subsection{Selection and Study of Component}

It contains that selection of component for application where we have to use that component, and with that it is also be for mass production.

After the selection of component, we have to study the component which means the dimensions of component and material and so on. Lastly we will be going through the reverse engineering process to design the progressive die.

\subsection{Selection of Sheet Metal Operations}

After study of component, select sheet metal operations which has to done on the component like piercing, blanking, bending, etc after the selection of operations we can procced to next stage of consideration of manufacturing stages.

\subsection{Consideration of Manufacturing Stages}

Manufacturing stages consists of the further design processes which consists of stages like feeding of strip, piloting the strip , further operations with blank stages were we give some relaxation to strip analyse that there should not be any error in the operations to be done on strip. 


\subsection{Blank Development}

Component contains the bending operation and another operations in which the length of component changes, so in reverse engineering we have to remove that bending and make it straight for sheet metal operation and also it has to fit into the plane sheet of metal. The drawing below is given for understanding the actual component which we have to manufacture[13].

To find blank length of component, we use to find out bend allowance and flange length.

\subsection{Developed Length $(a)=[(t \div 3)+(r)]^{* 1.5708}$}

Where,

$$
\begin{array}{lll}
\mathrm{a} & =\text { developed length (Bend Allowance) } \\
\mathrm{x} \& \mathrm{y} & =\text { length measured by section view (flange length) } \\
\mathrm{x} \& \mathrm{y} & =4.54 \mathrm{~mm} \& 7.09 \mathrm{~mm} & \\
\mathrm{t} & =\text { thickness of sheet } \quad=0.3 \mathrm{~mm} \\
\mathrm{r} & =\text { inner radius } \quad=0.3 \mathrm{~mm}
\end{array}
$$

Developed length $(\mathrm{a}) \quad=[(0.3) \div 3)+0.3]^{*} 1.5708$

$$
=0.6283 \text { or } 0.63 \mathrm{~mm}
$$

Total blank length

$$
\begin{aligned}
& =a+x+y \\
& =0.63+4.54+7.09 \\
& =\mathbf{1 2 . 2 6} \mathbf{~ m m}
\end{aligned}
$$

$\mathrm{K}$ factor calculation is the important aspect of the design of bending movement because it decides the blank depth and also we get to know the idea of dimensions of the component after bending is being done.

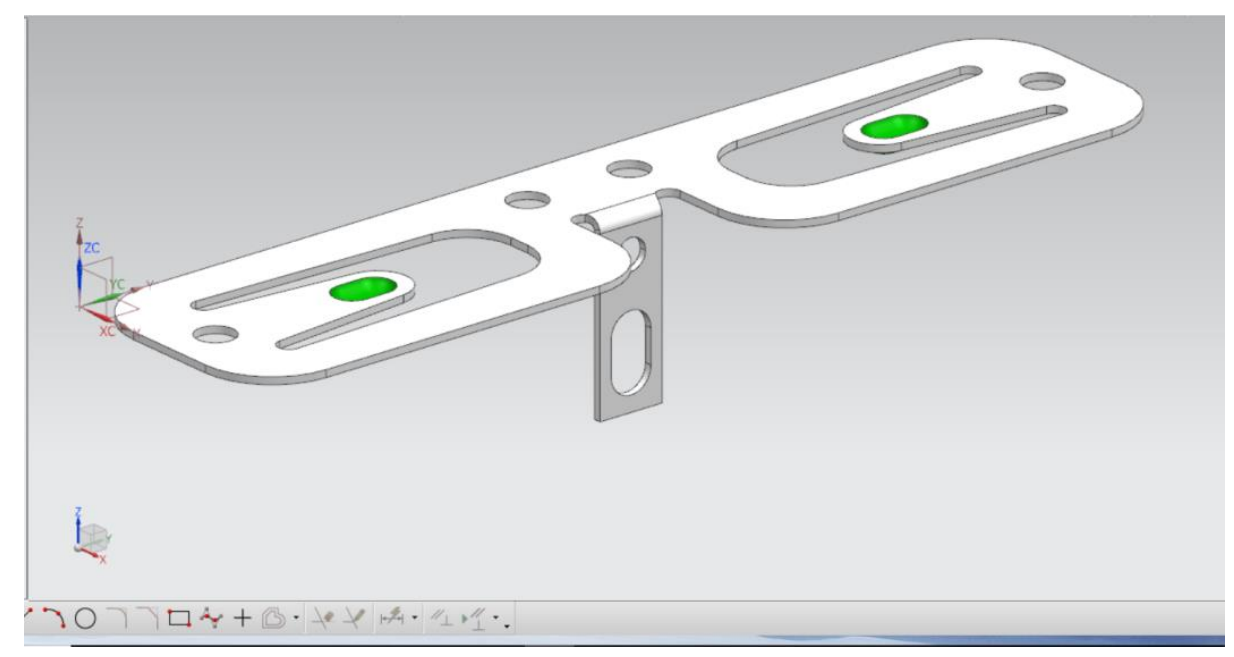

Figure 3.1: Component without Blank 
For blank development the component having some bending operations which have to be convert into plane of sheet metal working, so have to remove that bend and then the blank is form as given below:

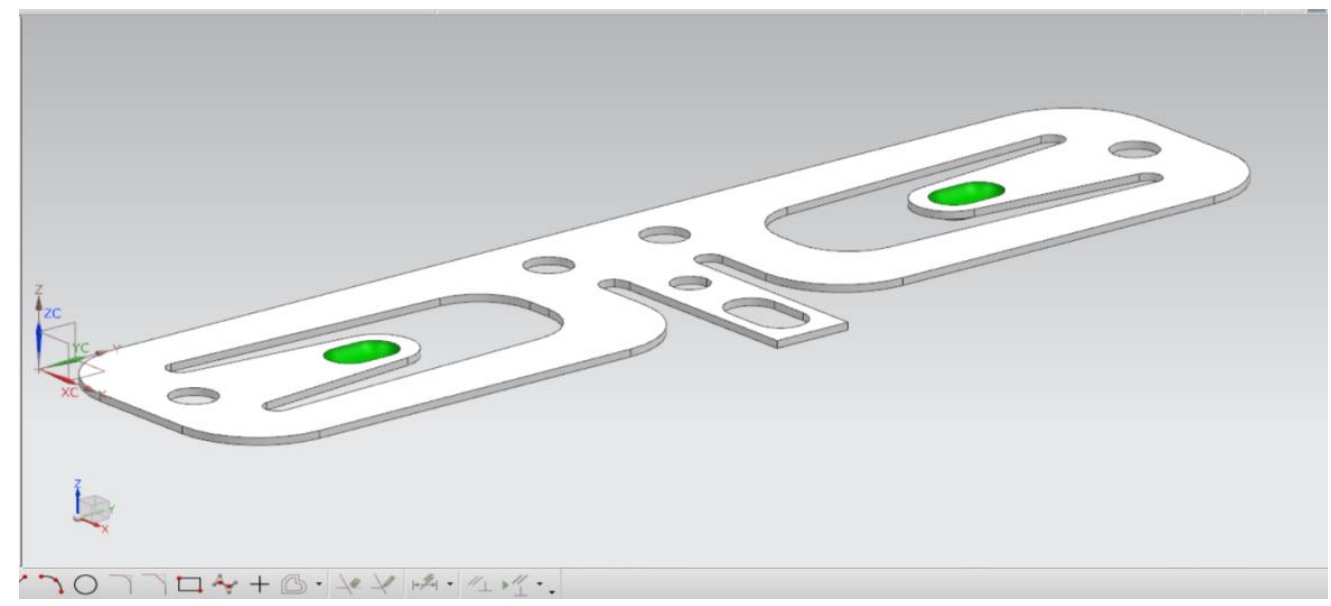

Figure 3.2: Component with Blank Develop

Blank development operation is done on any 2D or 3D software like AutoCAD and UG-NX CATIA, etc.

\subsection{Margin and Bridge Allowance:}

We have straight edge, our component width is $41.5 \mathrm{~mm}$. So, minimum bridge and margin should be taken as[12];

Margin or bridge $=1.5 *$ sheet thickness (minimum)

$$
\begin{aligned}
& =1.5 * 0.3 \\
& =0.45 \mathrm{~mm}(\text { minimum })
\end{aligned}
$$

So, we have taken the bridge and margin of $\mathbf{1} \mathbf{~ m m}$.

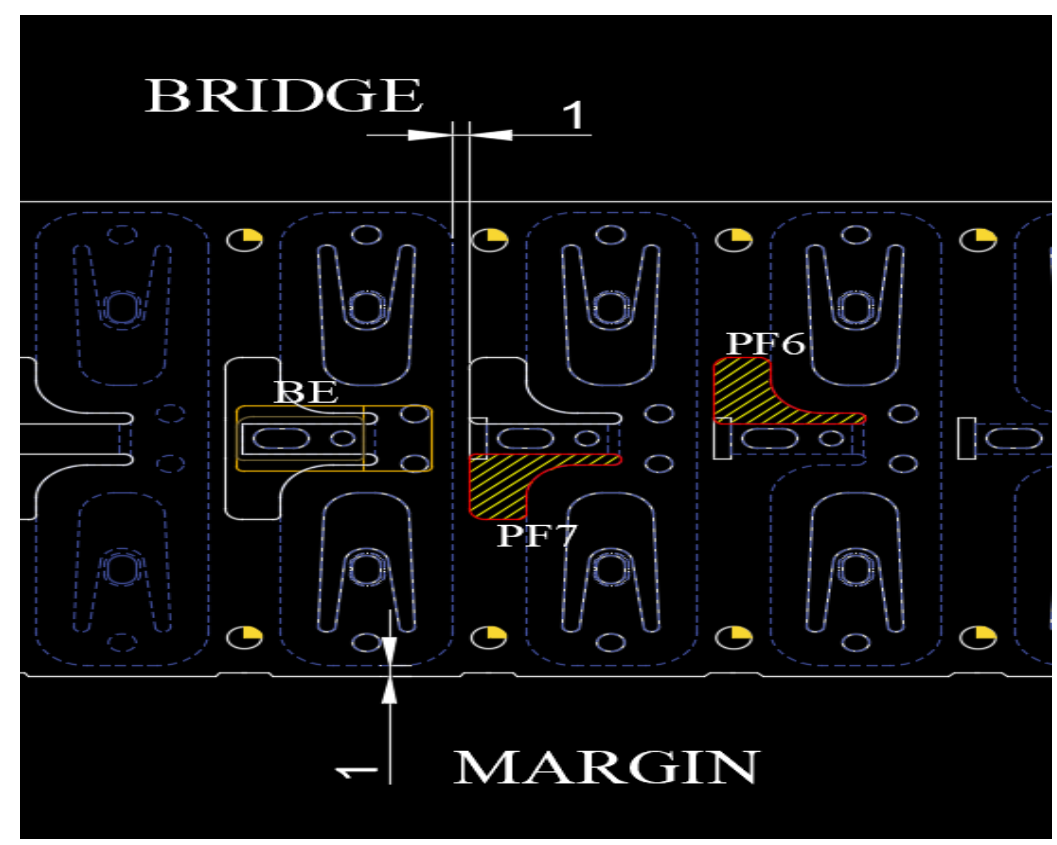

Figure 3.3: Margin and Bridge Allowance 


\section{Strip Layout}

Most stampings are made of steel. Carbon content varies from AISI-SAE 1010 to AISI-SAE 1030 and, therefore, most blanks are in the machine or cold-rolled steel range. Stampings are also made from these other materials:

- Aluminium

- $\quad$ Brass

- Bronze

- Copper

- Stainless steel

- $\quad$ Silicon steel

- Fibre

- $\quad$ Plastic sheet, etc.

*We have used copper rolled sheet because we need good electrical conductivity as our component is used for conduction of electricity.

To design strip layout, we have to find blank area;

Table 3.1: Blank Area Values

\begin{tabular}{|c|l|c|}
\hline SR, NO. & \multicolumn{1}{|c|}{ AREA } & $\mathbf{m m}^{\wedge} \mathbf{2}$ \\
\hline 1. & Outer area & 398.75 \\
\hline 2. & Four circles (Joining and Rivet ) & $-4 * 2.01$ \\
\hline 3. & Capsule shape & -5.06 \\
\hline 4. & Leg type & $2 * 41.9$ \\
\hline 5. & Single hole & 1.33 \\
\hline & Total Blank Area & $\mathbf{3 0 0 . 5 2}$ \\
\hline
\end{tabular}

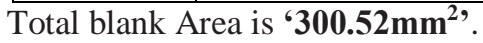

\section{Strip Economy}

Then we have design strip layout at various angles to find the maximum strip economy.

Strip Economy = Blank area $\div($ Pitch*Strip Width $)$

The major portion of the cost of stamping is material. Therefore, material economy is of the utmost importance from the standpoint of cost. Fifty to seventy percent of the cost of a stamping goes for material. The method employed for laying out the scrap strip directly influences the financial success or failure of any press operation. The blank must be positioned so that a maximum area of the strip is utilized in production of the stamping. A blank layout is drawn before any work is done on the die design itself. In fact, the scrap strip layout will govern the shapes and sizes of many of the die members. 
At an Angle 30 degree

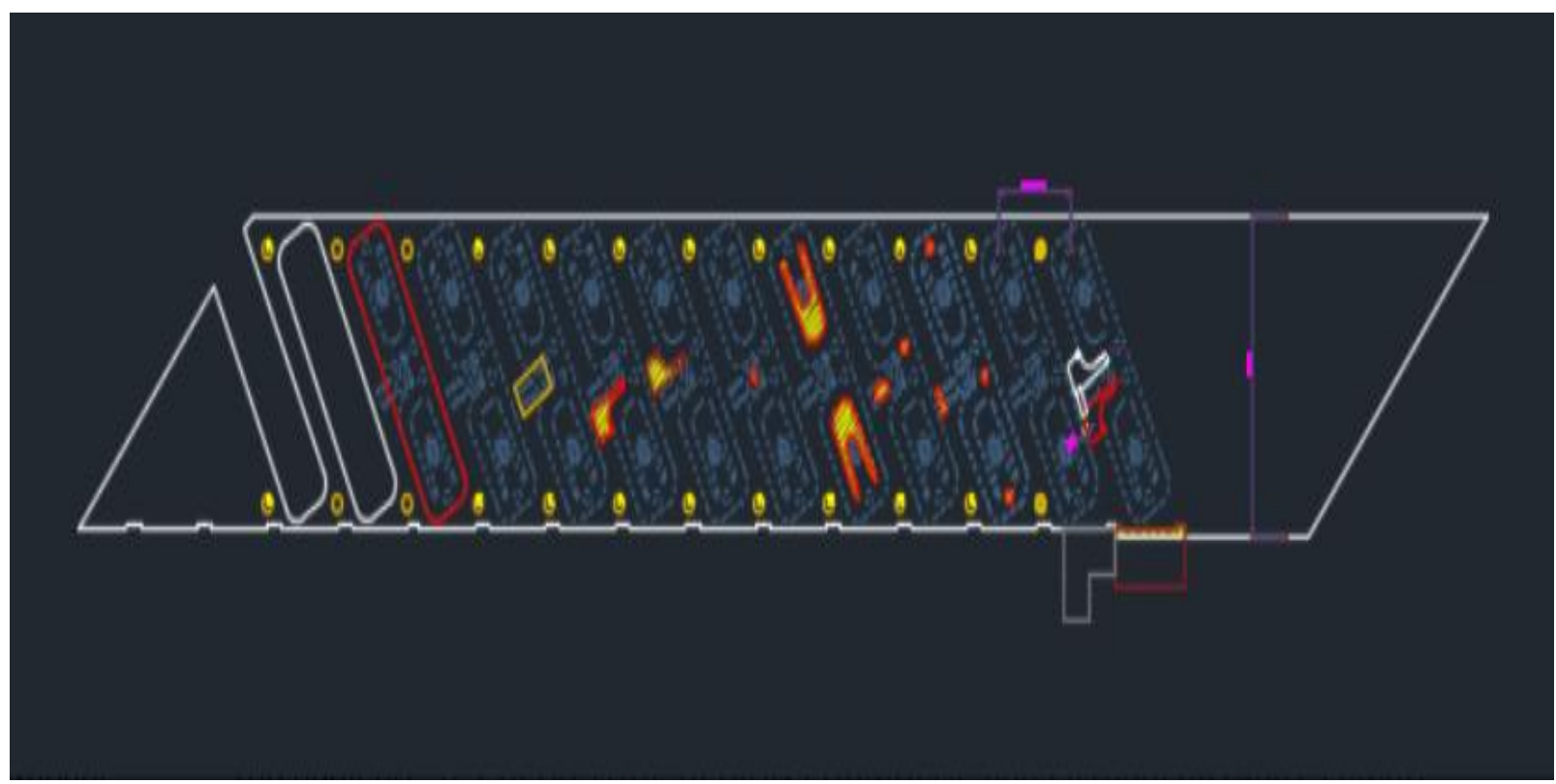

Figure 3.4: Strip Layout (Component Placed at 30 Degree)

Strip economy $\quad=[($ Blank area $)] \div[($ Pitch $) *($ Strip width $)]$

$=[(300.52)] \div[(42) *(16.4)]$

$=.4363$ or $\mathbf{4 3 . 6 3 \%}$

At an Angle of 0 degree i.e. Horizontal

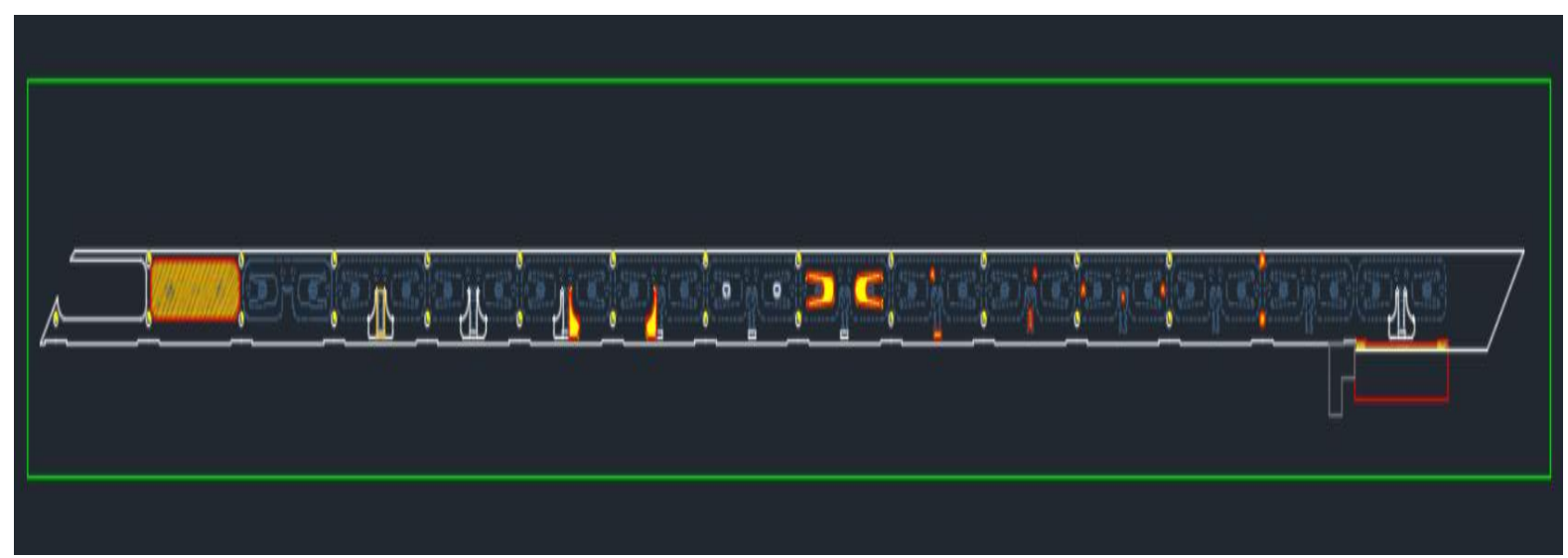

Figure 3.5: Strip Layout (Horizontal Component Placed)

Strip economy $=[($ Blank area $)] \div[($ Pitch $) *($ Strip width $)]$

$=[(300.52)] \div[(43.5) *(17.5)]=\mathbf{0 . 3 9 4 7}$ or $\mathbf{3 9 . 4 7 \%}$ 


\section{At an Angle of 90 degrees:}

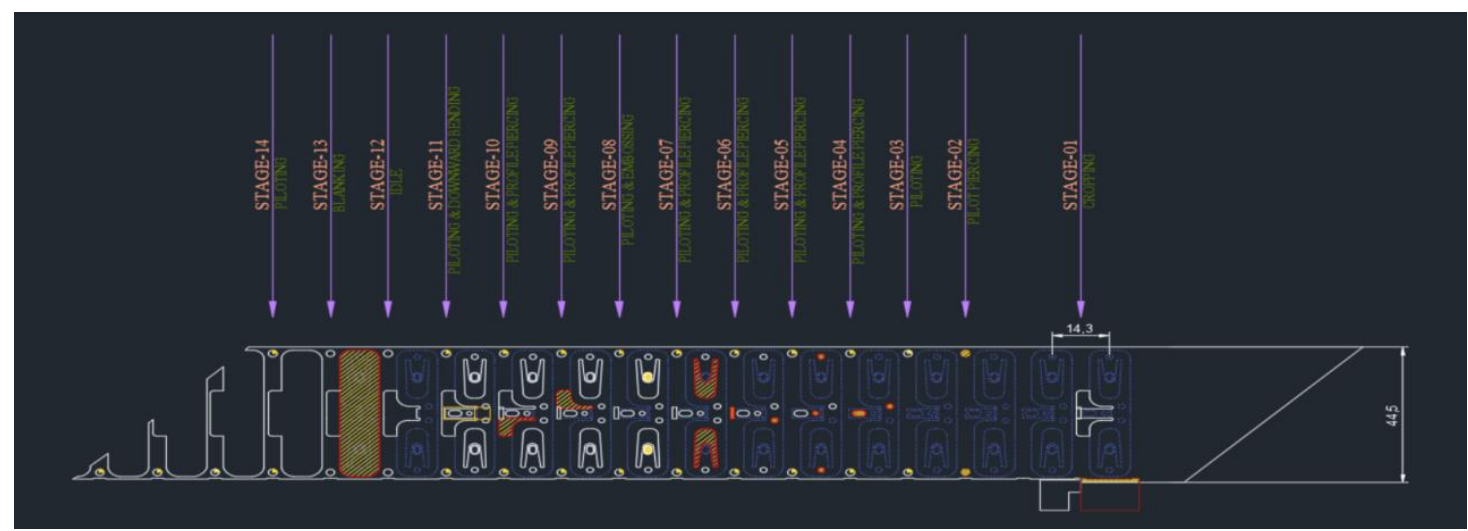

Figure 3.6: Strip Layout (Vertical Component Placed)

Strip economy $\quad=[($ Blank area $)] \div[($ Pitch $) *($ Strip width $)]$

$=[(300.52)] \div[(14.3) *(44.5)]$

$=\mathbf{0 . 4 7 2 2}$ or $\mathbf{4 7 . 2 2 \%}$

*So we have used the angle of our component to be 90 degrees because of its maximum economy i.e. $47.22 \%$

\subsection{Force Calculations}

\section{- Cutting Force}

The force required to be exerted by the punch in order to shear out the stock can be estimated from the actual shear area and shear strength of the material by using formula[5],

\section{Cutting Force $=\mathbf{P} * \mathbf{t}^{*} \mathbf{T}_{\max }$}

Where,

$\mathrm{P}=$ Total cutting edge perimeters

$\mathrm{t}=$ Thickness of sheet; $\mathrm{T}_{\max }=$ Shear stress $(172 \mathrm{Mpa})$

Cutting force $=334 * 0.3 * 172=\mathbf{1 7 2 3 4 . 4} \mathbf{N}$

- Stripping Force

Stripping Force $=25 \%$ of cutting force

Stripping force $=0.25 * 17234.4=4308.6 \mathbf{N}$

- Bending Force

Bending force required to bend a work piece depends upon the thickness of the work piece. The bending force will be calculated from the knowledge of material properties and the die characteristics. Bending force can be calculated using formula,

Bending Force $=0.333 * \mathrm{~S} * \mathrm{~L} * \mathrm{~T}$ 
Where,

\author{
$\mathrm{S}=$ shear stress \\ $\mathrm{L}=$ bend length \\ $\mathrm{T}=$ sheet thickness \\ Bending force $=0.333 * 320 * 7.7 * 0.3=\mathbf{2 4 6 . 1 5 3 6} \mathbf{~ N}$
}

\title{
- Press Capacity
}

The capacity of the press is the ability to deliver enough force necessary to perform the metal working operation. And the press machine should be capable of delivering about 33\% more force than the required for consistent performance. The plan is to design a progressive die for the multiple operation in a single stroke of the ram, the individual values for shearing and bending should be added.

Press capacity $=1.3$ times the cutting force $=1.3 * 17234.4=22404.72 \mathrm{~N}$

or

Press capacity $=$ cutting force + stripping force + bending force $=\mathbf{2 1 7 8 9 . 1 5 ~} \mathrm{N}$

We are using the maximum value i.e $22404.72 \mathrm{~N}$ which is also equal to $2240.472 \mathrm{Kg}$.

So we are going to select the press of $\mathbf{3}$ tonnes.

\subsubsection{Selection of Materials for Die Components}

\section{Relation between die failure mechanisms and properties of materials of die components}

The relationship between die failure mechanisms and properties of materials of die components in the present investigation is discussed as under.

\section{Abrasive Wear}

This type of wear dominates when the sheet material is hard and/or contains hard particles such as oxides or carbides. Abrasive wear is dominant with sheet materials such as hardened steels, spring steels etc. The tool steel properties that are important for good resistance to abrasive wear are high hardness, high volume of carbides, high hardness of the carbides and large carbide size.

\section{Adhesive Wear}

Adhesive wear occurs with soft and adhesive sheet materials such as aluminium, copper, stainless steel and low carbon steels The mechanical properties of die components that are critical for good resistance to adhesive wear are high hardness, low coefficient of friction between the tool and work material, and high ductility.

\section{Mixed Wear}

It should be noted that not all sheet materials cause purely abrasive or purely adhesive wear. Some cause partly adhesive and partly abrasive wear. This type of wear is designated as mixed wear. 


\section{Chipping}

Chipping often occurs after the die has been in service for a relatively short time Small cracks are initiated in the working surface of the die and further growth finally results in pieces chipping out. One tool steel property that gives a good resistance to chipping is high ductility.

\section{Plastic Deformation}

Plastic deformation occurs when the yield strength of the tool steel has been exceeded. Plastic deformation causes damage to or shape changes on the working surfaces of the tool The tool steel property that is important for a good resistance to plastic deformations is high hardness.

\section{Cracking}

The formation of cracks is very much enhanced by the presence of stress concentrators, e.g. grinding marks and machining marks or design features such as sharp comers or radii EDM layers on the tool surface are also a frequent cause. The tool steel properties that give a good resistance to cracking are low hardness, and high micro structural toughness But low hardness will have a detrimental effect on the resistance to the other failure mechanisms Thus working with a low hardness is not normally a good solution It is better to use steel with a good micro structural toughness.

\section{Galling}

Galling is a problem associated with soft and adhesive sheet materials. It normally appears as a gradual build up of small fragments of the sheet material, which are tom off and adhere to the working surfaces of the die components. A low coefficient of friction between the tool surface and the sheet metal helps to prevent galling[28].

\subsubsection{Steps for Selection of Materials}

The selection of materials for progressive die components for a given application Depend on which die failure mechanisms dominates. It requires more than just knowledge of materials properties. The step-by-step manual process of material selection for progressive die components is investigated during industrial visits and discussion with die design experts and is given as under.

\section{Step 1. Identify the type of wear}

This is the most fundamental step because it will determine which wear resistance profile the die material should have. The following factors are considered to establish the dominating wear (abrasive, adhesive or mixed) to be expected:

- Type of sheet material

- Hardness of sheet material

\section{Step 2. Occurrence of Chipping or Plastic Deformation}

The following factors determine the extent of the risk for chipping and/or plastic deformation, i.e. whether high ductility and/or high hardness are needed:

- Type of operations to be performed on progressive die

- Thickness and hardness of sheet material

- Geometrical complexity of parts to be produced 


\section{Step 3. Risk of Cracking}

The following factors give an indication of the risk for cracking, i.e. whether tough material and/or moderate hardness levels have to be used[28]:

- Type of operations to be performed on progressive die

- Die design and die size

- Thickness and hardness of sheet material

Table 3.2: Materials Used in Plates

\begin{tabular}{|c|l|c|c|}
\hline Sr no. & Plates & Material & Hardness \\
\hline 01 & Die plate & K110 & $58-61$ HRC \\
\hline 02 & Bottom plate & C45 & $172-207 \mathrm{HB}$ \\
\hline 03 & Punch plate & $\mathrm{C} 45$ & NA \\
\hline 04 & Stripper plate & HcHCr & $56-62$ HRC \\
\hline 05 & Thrust plate & EN31 & $61-63 \mathrm{HRC}$ \\
\hline 06 & Top plate & C45 & $172-207 \mathrm{HB}$ \\
\hline
\end{tabular}

3D Modelling

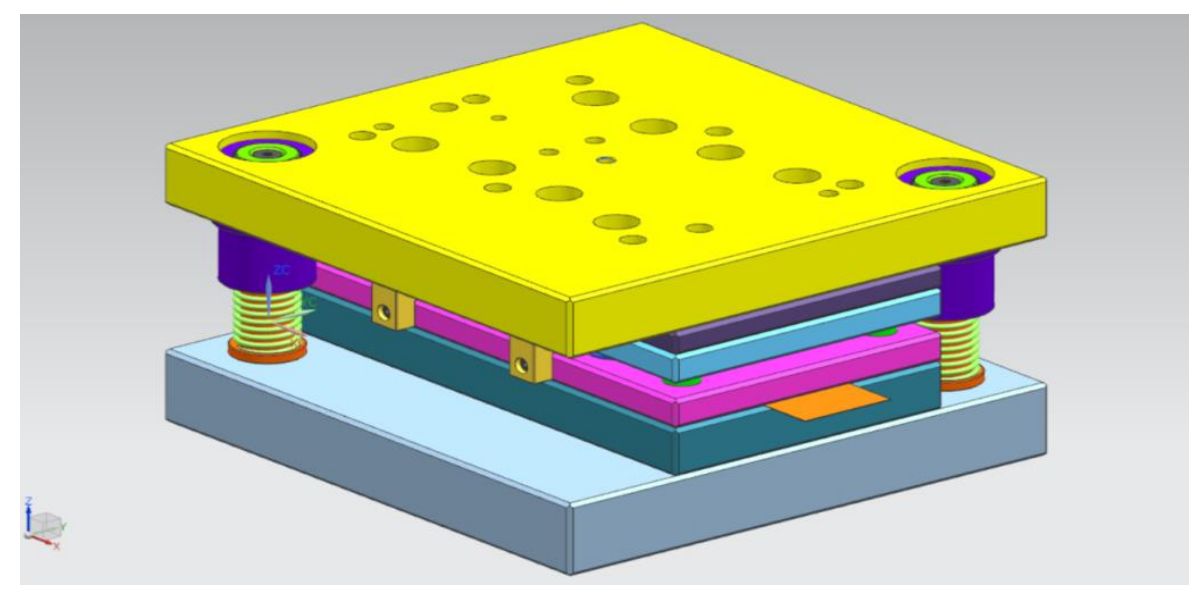

Figure 4.27: Assembly of Progressive Die

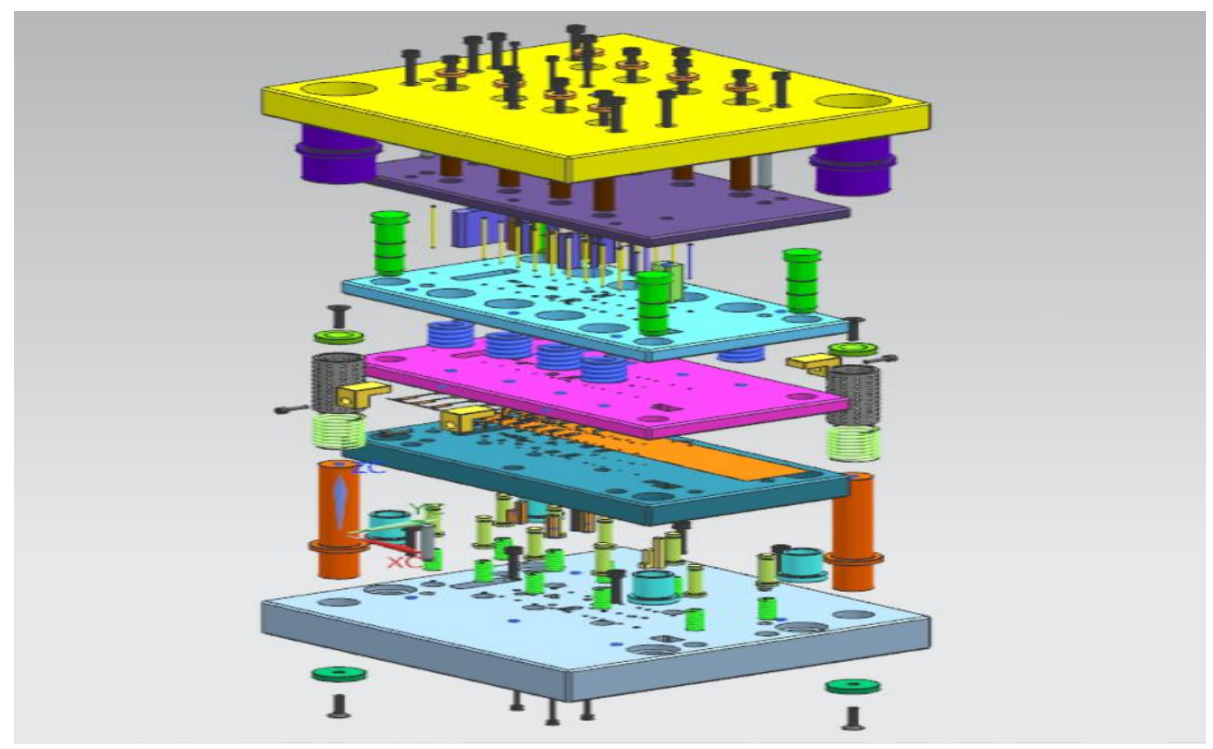

Figure 4.28: Explode View of Assembly 


\section{CONCLUSIONS}

From the above discussion all the four operations viz. Piercing, Embossing, Bending, and Blanking were done by four different dies. These operations require separate labour to handle these operations. But the combination of these operations in to one single progressive die will be beneficial to the industries. The progressive die manufacturing is a great alternative to improve the productivity and also to reduce labour cost. This progressive die was designed using UG-NX and AUTOCAD Computer Aided Design (CAD) software. Total 32 parts were modelled and then they were assembled to produce final progressive die. The designed die was very effective and reduced manpower from 7-8 workers to 2 workers only. This has reduced labour cost and has also reduced effective cycle time and thus increased the production rate. Ultimately, productivity of the industry is increased.

The manufacturing cost of floating contact switch with progressive die has reduced. So there is a reduction in overall manufacturing cost per component. Although progressive die have very high initial cost and complicated design but it can make up with time and ultimately will be profitable for the industry. In progressive die the initial proving cost is high, it is rarely used in small scale industries. Since progressive dies produce parts in batch as well as in mass production it is not used in variable production. The choice of an efficient strip layout is an important step during die design, because as only the optimum layout can reduce wastage of the strip material and reduce the overall cost of production.

\section{Future Scope}

There should be some error of burr on blank. So there is some problem in die clearance and there is problem in guiding the strip over the die surface. A system can be developed for analysis of die design data from strength point of view using Finite Element Analysis (FEA) or some other suitable approach. Investigations can be made for prediction of die stresses and die life A post processor program can be developed, which is capable of connecting the outputs of the proposed knowledge-based system to the Computer-Aided Manufacturing (CAM).

\section{REFERENCES}

1. Mozhgan Nozari, Amir Abbas Shojaie and Sadigh Raissi "To Priority the Success Factors in the Design of Progressive Die by DFSS Methodology”,journal of Aspects in Mining \& Mineral Science (February 9,2018).

2. Pravin R Lokhande, S Balaguru, G Deenadayalan, A review of contemporary fatigue analysis and biomaterials studies in endodontics, Materials Science Forum. 969 (2019) 93-98.

3. K. Kishore Kumar, Dr. A. Srinath, M. Naveen,R. D. Pavankumar- "DESIGN OF PROGRESSIVE DIES”, International Journal of Engineering Research and Application (IJERA) (May-Jun 2012).

4. Pravin R Lokhande, Deenadayalan, Ratnakar R Ghorpade, S. R. Srinidhi, A review of contemporary research on root canal obturation and related quality assessment techniques, Lecture Notes in Mechanical Engineering. (2019) 11-25.

5. Vivek D. Barhate, Dr. Sachin G. Mahakalkar, Dr. A. V. Kale - "Design and Analysis of Progressive Die for an Industrial Part”,International Journal of Science and Research (IJSR) (10-11 April 2015)

6. Lokhande P R, Balaguru S., Deenadayalan, A comparative microleakage assessment in root canals obturated by three obturation techniques using fluid filtration system, Biomed Pharmacol J. 12 (2019) 49-56.

7. S. Kumar, R. Singh - “A knowledge-based system for selection of progressive die components”,Journal of Achievements in Materials and Manufacturing Engineering (15.11.2006). 
8. Pravin R Lokhande, S Balaguru, G Deenadayalan, Ratnakar R Ghorpade, A review of contemporary researches on biomedical image analysis, CSIS. (2019) 84-96.

9. Pravin R Lokhande, S Balaguru, 2019 A mathematical model for root canal preparation using endodontic file. Journal of Oral Biology and Craniofacial Research. 43 (20) 21-27. 